\title{
Being a Dyslectic in Norwegian Secondary School
}

\author{
By Kitt Margaret Lyngsnes ${ }^{*}$ \& Siv Kristin Skjelvåg ${ }^{ \pm}$
}

Dyslexia is a common learning difficulty. A The purpose of this study is to explore the experiences of young people with dyslexia in secondary school in a Norwegian context and provide insight that might be used to support the students. The research question for the study is as follows: What experiences do dyslectic students have in secondary school regarding their dyslexia? A phenomenological approach was adopted to explore dyslectic students' experiences. Purposive sampling was used to identify 4 young people who met the chosen criteria. The data-gathering tool was individual semi-structured interviews. The data were analysed through a thematic step-by-step analysis process. Four themes with several subthemes concerning the experiences of young people diagnosed with dyslexia emerged. Theme 1: Personal coping strategies related to schoolwork. Theme 2: Foreign language torment. Theme 3: Emotional impact. Theme 4: Struggling with educational support. A main finding of this study is the significance of teacher competence for students with dyslexia. The study has identified the need for teachers to understand the students' learning difficulty, provide alternative tasks and have competence in how to use software teaching aids to support pupils with dyslexia.

Keywords: adaptive teaching, dyslectic students, dyslexia, phenomenology, secondary education

\section{Introduction}

In Norway nearly all children aged 6-16 attend municipal public schools. Less than 4 per cent of pupils are enrolled in a private school. The compulsory education includes a primary level (grades 1-7, age 6 to 12) and a lower secondary level (grades 8-10, age 13 to 16). The Norwegian national curriculum emphasizes two central principles. One of them is about inclusion building based on the Salamanca Statement, which expresses that all pupils regardless of disabilities or learning difficulties are to have inclusive education to secure equal educational rights (UNESCO, 1994). All children shall attend their local school and be a member of an ordinary class. The other significant principle is about adaptive teaching. Teaching shall be individually adapted, which includes, if necessary, special education. Norwegian pupils are only supposed to receive special education when they do not benefit from the ordinary teaching. Special education is mostly a part time activity, and mainstreaming is the ideal (Haug, 2020). Sometimes different learning difficulties, behaviour problems or other challenges are detected and become so extensive that the pupils do not benefit from the ordinary teaching. In such cases the school psychological service carries out tests and analysis and writes an expert report about the pupil in question. It is based on this report the

\footnotetext{
*Professor, Nord University, Norway.

${ }^{ \pm}$Teacher M.A., Steinkjer Secondary School, Norway.
} 
local school authorities make a formal individual decision concerning whether a pupil shall receive special education in any form and/or be provided different kinds of support and assistance.

Reading difficulties are among the most common learning difficulties that might lead to extra support in school. Proficiency in reading is a fundamental skill in today's society. Learning to read is one of the key outcomes of the first years in school. Children who have difficulties with reading begin to experience various failures early in their education, and if no support is provided, they might enter a downward spiral that leads to low educational attainment and subsequently poor employment prospects. There are different causes for reading difficulties such as, for example, a lack of schooling, poor teacher competence, mental or hearing impairment, and a series of other factors. One specific reading difficulty is dyslexia.

The aim of the current study is to explore the experiences of young people with dyslexia in secondary school in a Norwegian context via a phenomenological study that provides insight that might be used to support the students. The research question of the study is the following: What experiences do dyslectic students in secondary school have with regard to their dyslexia?

\section{Literature Review}

Dyslexia occurs worldwide irrespective of culture, gender or nationality. There is no universally agreed definition of dyslexia, and this makes it difficult to determine its true prevalence. However, the World Health Organization (WHO) considers dyslexia a developmental learning disorder with impairment in reading characterised by significant and persistent difficulties in learning academic skills related to reading, such as word reading accuracy, reading fluency, and reading comprehension. The WHO points out that dyslectic individuals' performance in reading is markedly below expectations for their chronological age and level of intellectual functioning. Moreover, this is not due to an intellectual development disorder, sensory impairment (vision or hearing), neurological disorder, lack of available education, lack of proficiency in the language of academic instruction, or psychosocial adversity (WHO, 2018).

The term dyslexia thus describes a learning difficulty that is characterized by difficulties in accurate word recognition, spelling and decoding abilities (Reid, 2011). The two main types of reading difficulty are problems with word-level decoding and problems with reading comprehension. Some individuals experience both (Hulme \& Snowling, 2016). Common observable symptoms of dyslexia are poor reading fluency and spelling. Since there is no universally accepted definition of dyslexia that is precisely formulated and operationalised, the prevalence of dyslexia is difficult to establish (Elliott \& Grigorenko, 2014). It is best conceptualised as occurring in terms of a continuum rather than as a distinct category of learning difficulties. Reading difficulties tend to be continuously distributed in the population (Fletcher, Lyon, Fuchs, \& Barnes, 2019). According to Hulme and Snowling (2016), the criteria used for diagnosis are to some extent arbitrary, just as those for obesity or hypertension. This requires placing a cut point on a continuous 
distribution to determine the presence of a condition. Where the cut point is placed can affect prevalence estimates (Wagner et al., 2020). The prevalence depends upon the severity or cut-off used for identification. When searching for prevalence of dyslexia, rates ranging from less than $5 \%$ to $20 \%$ are found. A common criterion for diagnosing dyslexia is a reading accuracy greater than 1.5 SD (standard deviation) below the mean, which results in roughly $7 \%$ of the population being dyslectic (Hulme \& Snowling, 2016; Peterson \& Pennington, 2012; Snowling \& Melby-Lervåg, 2016).

Dyslexia runs in families. There is a heightened prevalence of dyslexia in children with a dyslectic parent, with some 44\% developing dyslexia (Snowling \& Melby-Lervåg, 2016). Nevertheless, genes act through the environment. Hulme and Snowling (2016) point out that parents with dyslexia not only share genes with their offspring but may also plausibly provide a different home literacy environment compared to that found in homes where parents do not experience literacy difficulties. Similarly, children who are poor readers are less likely to seek out opportunities for reading than good readers. Low levels of exposure to books and reading practice will, in turn, compromise reading development (Hulme \& Snowling, 2016).

Although genes increase the probability of dyslexia, several studies have shown that early educational interventions and training are effective (Hulme \& Melby-Lervåg, 2015). Oral language weaknesses, which are precursors of dyslexia, can be observed in the preschool period (Hulme \& Snowling, 2016), and screening for language difficulties at school entry might identify children who are at risk. Research into methods that improve the symptoms associated with dyslexia has shown the positive impact of interventions on dyslectic children (Duff \& Clarke, 2011). According to Torgesen (2002), there are some key elements in successful reading intervention for struggling readers. Intervention should be explicit, meaning skills taught directly, which more intensely implies that increased learning opportunities be provided, preferably in smaller teaching groups. Additionally, there is a need for support both academically, via scaffolded learning, and emotionally. Evidence also suggests that interventions should supplement and not replace general classroom literacy instruction (Brooks, 2013; Duff \& Clarke, 2011). In an extended study of teachers in UK, Knight (2018) found that teachers had limited insight into dyslexia, as they held a just basic understanding of the learning difficulty based on the behavioural issues associated with it. White, Mather, and Kirkpatrick (2020) also concluded that the success of students with dyslexia is dependent upon the knowledge and skills of the school practitioners responsible for their academic programmes.

Numerous studies of children and young people with reading difficulties show that they often experience stressful situations and failures that lead to negative emotions and doubt of their own ability to learn, which in turn affects their motivation and self-efficacy (e.g., Alexander-Passe, 2008; Kim \& Lorsbach, 2005; Ridscale, 2005; Skaalvik, 2004). 


\section{Methodology}

A phenomenological approach was adopted for this study to explore the dyslectic students' experiences. Phenomenological approaches are used to understand phenomena from the perspective of those who experience the phenomena, with understanding achieved primarily through interpersonal interviews. The aim of a phenomenological study is to describe the common meaning of lived experiences for several individuals. The data collected can describe the shared meaning of the experience from several individuals' perspectives in order to present commonalities. It does not aim for generalisability but to shed light upon the world as experienced by the individuals studied (Creswell \& Poth, 2018).

The participants in an in-depth phenomenological study usually are quite few. Dukes (1984) recommends between three and ten. In the current study purposive sampling was used to identify four young people who met the following criteria: students in secondary school diagnosed with dyslexia by the school psychological service and thereby given access to support and provided with extra teaching aids. Furthermore, they should have insight into their learning difficulty and no further problems in school subjects. The students were recruited from two Norwegian secondary schools. The headmasters decided on potential participants through enquiries with the teaching staff. The researchers thereafter contacted the parents by phone to inform about the project. The parents were positive and gave permission to ask their children if they wanted to participate in an interview. The final sample consisted of three girls and one boy aged 14-16 years. Three of the pupils that were interviewed had a parent with dyslexia. Some also had siblings with this learning difficulty. Information on the four research participants is presented in Table 1.

Table 1. Participant Characteristics

\begin{tabular}{|l|c|c|c|c|}
\hline Participant & Gender & Age & Grade & Grade at diagnosis \\
\hline P1 & Female & 15 & Grade 9 & Grade 7 \\
\hline P2 & Male & 14 & Grade 8 & Grade 2 \\
\hline P3 & Female & 16 & Grade 10 & Grade 10 \\
\hline P4 & Female & 15 & Grade 9 & Grade 6 \\
\hline
\end{tabular}

The data-gathering tool was individual semi-structured interviews. The interview-guide contained relevant topics about subjects, the learning environment, motivation, relations, support, digital software, etc. Using this partly structured topics list, the students were encouraged to elaborate on their experiences. The interviews were conducted with a format similar to a conversation, and the participants were invited to reflect on situations and examples raised both by themselves and the researchers. Thus, it was possible to follow topical trajectories in the conversation that strayed from the guide and allow the participants to express their views in their own terms. This approach encouraged the participants to reflect on their own experiences while permitting the researchers to gain indepth knowledge of the students' lived experience of dyslexia. The interviewer encouraged the students to express their in-depth experiences with questions such 
as the following: "Can you describe that?" "How did you feel then?" "Can you tell me more," and "Could you give an example?" All interviews were digitally recorded and transcribed verbatim including expressions of laughter, sighs, and silence. Each interview lasted between 30 and 40 minutes.

While all phenomenological analysis involves reflection, different variants privilege either the use of systematic procedures or the spontaneous emergence of creative intuition (e.g., Giorgio, 2009; Van Manen, 2014). In this study the data were analysed using a modified version of Hycner's step-by-step explicitation process (Groenewald, 2004). The first step was to listen to the recordings and read the transcripts of each interview carefully to become familiar with the words of the student in order to develop a holistic impression. Thereafter a line-by-line analysis was used to find units of meaning from each interview. Then these units of meaning were grouped together into clusters of themes. Finally, data were categorised into themes and subthemes. Several analysis sessions were conducted, and the meaning was interpreted by asking what the themes revealed about the nature of the students' experience. Modifications were made in the structure of themes and subthemes, through examining similarities and differences, and thereby the final structure of four themes was determined. The data analysis process was characterised by an openness and sensitivity to the text and a movement between the whole and the parts (Dahlberg, Dahlberg, \& Nyström, 2008; Van Manen, 1997).

This study was approved by the Norwegian Social Science Data Services. Both the parents of the four participants and the students themselves provided written informed consent prior to participation in the study and were informed that they could withdraw from the study at any time. Confidentiality of data was described, and anonymity was ensured in all phases of the study.

\section{Results}

Through the thorough analysis, four themes with several subthemes concerning the experiences of young people in secondary school diagnosed with dyslexia emerged. These themes and subthemes are presented in Table 2.

Table 2. Summary of Themes and Subthemes

\begin{tabular}{|l|ll|}
\hline \multicolumn{1}{|c|}{ Themes } & \multicolumn{1}{c|}{ Subthemes } \\
\hline $\begin{array}{l}\text { Theme 1: Personal coping strategies related } \\
\text { to schoolwork }\end{array}$ & $\bullet$ & Family help with homework \\
\hline \multirow{2}{*}{ Theme 2: Foreign language torment } & $\bullet$ & Listening carefully to teachers \\
& $\bullet$ & Deeping your head down" \\
\hline Theme 3: Emotional impact & $\bullet$ & Writing down how words are pronounced \\
\hline \multirow{2}{*}{$\begin{array}{l}\text { Theme 4: Struggling with educational } \\
\text { support }\end{array}$} & $\bullet$ & Disclosure \\
& $\bullet$ & - Self-consciousness and distress \\
\hline
\end{tabular}




\section{Personal Coping Strategies with Schoolwork}

The sub-themes family help with homework, listening carefully to teachers, and "keeping your head down" illustrate how the students cope with their schoolwork. All of them found that the dyslexia affected their schoolwork. They experienced that problems with reading, spelling, and writing had a considerable effect on their comprehension of tasks and their progress both at school and when it came to homework.

It was evident that the four young people had in different ways developed their own personal strategies for coping with how their learning difficulties affected their schoolwork. They described their coping strategies and how these were used to manage their schoolwork in one way or another.

One of the participants had difficulties reading texts. She had access to audiobooks in different subjects, but she disliked listening to them because she found them so monotonous and tedious. Her solution was the following:

"When it comes to homework, daddy reads and explains for me how the tasks are to be done. And when we are going to have tests in geography or history, he reads the text pages for me. Even if I send a message on SMS or Messenger, I want daddy to check the spelling."

One of the other students had another strategy. He had a strong auditive memory and therefore listened carefully to the teachers during the lessons.

"I understand and remember things I hear. When I concentrate and listen to what the teachers say, I do not have to read so many texts myself. I learn by listening."

Avoidance was used as a strategy to reduce immediate problems. The participants described different ways of "keeping your head down". One of these strategies was to "pretend to listen" or to "pretend to do the given tasks". The reasons why they pretended was that it was difficult to concentrate over time and tasks often involved texts that had to be read. In line with this pretending was the strategy of dodging tasks and homework. They often felt reluctant when it came to asking for help. It was an uncomfortable feeling to be the one that had problems and needed help. To avoid this, one strategy was not to do the work and thus not have to ask for help.

\section{Foreign Language Torment}

The sub-themes dreading the lessons, writing down how words are pronounced, and watching English films are expressions of struggling with foreign languages. Common for the Norwegian students with dyslexia was trouble related to learning a foreign language. In Norway it is mandatory for children to start learning English in the $2^{\text {nd }}$ grade, and from the $8^{\text {th }}$ grade they can choose to learn an additional foreign language. All four participants in the study therefore had to learn English. In addition to English one of them had chosen French as well. 
Generally, they found the foreign languages challenging and stressful. The trouble they pointed to was that the words in English are written so differently from how they are pronounced, and since they had difficulty reading and writing Norwegian words, a foreign language felt impossible.

"I'm dreading the English lessons. I hate it because I never know when I have to say anything in English. And when I have to write English.... When I get English exercises back from the teacher, my text is underlined everywhere to show what is wrong. But I do not know what is wrong!"

One of the other students had a different experience. He had what he characterised as "a dyslexia-friendly" teacher in English. This teacher produced easier texts and tasks for him.

Another experience was that developing a special personal coping learning strategy for English was helpful: "I think about what Norwegian words the foreign words resemble. It is easier to remember the words that way. Then I write the words down in the way they are pronounced. Like this I can speak the language, but I cannot spell it".

Watching English films was pointed out by the students as a way of learning English. In Norway, foreign language films are provided with subtexts in Norwegian. Since these students were not able to read the subtexts, watching English films was considered a useful and pleasant exercise.

\section{Emotional Impact}

Disclosure, self-consciousness, and distress are subthemes illustrating the emotional impact dyslexia had on the students. Disclosure or non-disclosure of their learning difficulties was an issue for the four young people in this study. None of them denied the fact that they had dyslexia. On the other hand, they were not overly open about it. They had some degree of discomfort in disclosing their disability to friends and classmates. One participant had friends both in class and outside school that knew she had dyslexia. She was, however, eager to conceal the diagnosis and was content that she did not think all the classmates knew that she was dyslectic, "I try not to think so much about dyslexia, really!"

In line with the issue of disclosure was the feeling of self-consciousness about their dyslexia, and inadequacy they experienced when compared with their schoolmates. One of them expressed her struggle in this way:

"I think it is hard to be a dyslectic. I wish I was equal to my classmates and could be as clever in English as they are. But I can't! In school I am quiet, a bit self-conscious. I don't like to speak out or say anything at all in class. I never raise my hand to say something. Outside school in leisure time, on the other hand, I am quite chatty and vivacious."

Not all of them experienced negative feelings and stress to the same degree. One student felt that the dyslexia did not affect him much emotionally: "I think it's quite OK actually." Another participant felt that sharing the misery of dyslexia was 
a comfort and expressed that: "I feel better about the dyslexia now, because my best friend was diagnosed with it recently. Now we both know how the other one feels. That is so good!"

\section{Struggling with Educational Support}

The sub-themes, computers, and software available, ambivalence to teaching aids, and teacher's awareness and competence are all elements in the students' struggle with educational support. As a part of the schools' adaptive teaching, the four dyslectic students were equipped with a computer and a number of educational software programs developed to help them read, write and understand. However, a common experience among the students was that they did not make very much use of this equipment for different reasons. One of them wanted to use programs that corrected her spelling (named Lingdys and Lingright). "I need help to learn to use them. The teachers don't have any knowledge about how to do it, therefore I can't do it. I'd like to have some help!" Another experience was expressed like this:

"They are not good at dyslexia in my school. They try, but the teachers need to go to a course or something. They don't even find audible textbooks for me. My parents use to help me. My mum has tried to find a course about Lingdys and Lingright. But these courses are arranged far from where we live."

The participant who was diagnosed in the $2^{\text {nd }}$ grade had, on the other hand, made use of these programs for several years and found them very useful. He and his family had found out how they could be used. His experience was that schoolwork was simplified by such teaching aids:

"Things go so much better when I use such programs. In maths for example there are many tasks where you must read a text to grasp what the mathematical problem is. For me this reading takes much longer time than doing the maths, and often I misread and don't understand the problem. The program reads the text for me, and I can concentrate on the maths."

Another of the participants did not use her computer. She preferred to write by hand "because then no red lines emerge under the misspelled words. It is so discouraging to see all the mistakes I do". Several statements from the students underlined the fact that using audiobooks, software programs and other teaching aids that the other students did not use made them stand out as different from the others. They preferred to mask their dyslexia. One example of this concerns the student who had an agreement with her teachers to receive a handout before the lessons when the teaching involved texts and a certain amount of reading or writing. The teachers mostly forgot to give her this handout, and "I dislike reminding them. Instead, I try to write or read what I am able to do". 


\section{Discussion}

This study of young people with dyslexia aimed to shed light on their experiences as students in secondary school in Norway. Several important themes were identified: the students had developed different coping strategies, they had problems with foreign languages, the dyslexia had an emotional impact on them, and they struggled in different ways with educational support related to their dyslexia. Feelings of distress and lack of confidence due to their reading and writing difficulties were common experiences. These difficulties not only affected their work with the school subjects and tasks, but also their self-confidence in relation to their ability to learn and interact with other young people.

Many of the strategies and emotions described by the students diagnosed with dyslexia could also be relevant for students without this specific learning difficulty. This includes the coping strategies related to "keeping your head down" when it comes to listening to the teaching or skipping tasks and homework. Moreover, some of the emotions described in this study are common to teenagers regardless of dyslexia. To feel insecure, wanting to fit in and be like the others is part of being a teenager. For young people with dyslexia, however, they have a diagnosis that can make these feelings even stronger. The results of this study indicate that the participants experienced dyslexia as a defining aspect of them in different ways.

The study shows that access to educational support was mostly helpful, but it was both scarce and contributed to their feelings of differentness and distress. As shown in Table 1, one of the students was diagnosed early, with the others much later. This person had learned to use compensatory teaching aids early and made good use of them. It was his family who helped him, however. The other students felt more uncomfortable and did not have the same skills when it came to using computers and software. Given that dyslexia can be observed in early childhood (Hulme \& Snowling, 2016), it is important that children are diagnosed early. Then appropriate teaching aids can be provided, teaching adapted, and educational support and interventions developed (Haug, 2020; Torgesen, 2002). The student who was diagnosed at an early age had best use of compensatory teaching aids. This is in line with research evidence shown by Hulme and Melby-Lervåg (2015) that educational interventions are more effective when they are introduced at an early stage.

A main finding in this study is the significance of teacher competence for students with dyslexia. The study has identified the need for teachers to understand the students' learning difficulty, provide alternative tasks and have competence in how to use software teaching aids to support pupils with dyslexia. Dyslexia is a common learning difficulty that is probably found in every class. Therefore, teachers need knowledge and training concerning how to facilitate learning for pupils with dyslexia. The young people in our study often missed adequate support and adaptive teaching. Research evidence points to the importance of supplemental interventions where explicit skills are taught directly to dyslectic pupils, preferably in smaller groups (Brooks, 2013; Torgesen, 2002). 
Since dyslexia affects a significant part of the population, openness about this learning difficulty is also important to reduce young people's distress over their problems. In Norway, the Prime Minister, Erna Solberg, has set an example by being straightforward about her dyslexia.

\section{Limitations of the Study}

There are some limitations of this study. The main limitation is the sample. The study reports findings from a small group. The four participants attended two different schools. These schools, however, were situated in the same city in the same municipality. It might have strengthened the study if the sample had consisted of more participants from other schools and geographical areas. In addition, studies based on self-report from participants are subjective. There might be tendencies towards selective sharing of experiences, where some unpleasant or pleasant thoughts, situations and experiences are expanded on or kept back (Morris \& Turnbull, 2006). Although the sample size was small, these findings can inform teachers, schools and municipalities and prompt thought about how it feels for teenagers to be dyslectic and how they might be supported. Furthermore, the results of the study show the need for more research on educational support for children and young people with dyslexia.

\section{Conclusions}

The current study shows that being dyslectic was challenging in many ways for the students. Two factors seem to be of special importance when it comes to educational support for dyslectic students. The first is the significance of getting an early diagnosis so that relevant support might be provided at an early stage. The other factor is the necessity of teacher competence. To secure adaptive teaching, teachers need to have knowledge about dyslexia, what interventions that are helpful, and how to use supplementary teaching aids. In line with Knight (2018) we will point out that good quality teacher training is essential so that teachers have a comprehensive understanding of the multi-layered aspects of dyslexia and proficiency in teaching dyslectic children and young people. That might be obtained through both pre-service and in-service teacher training.

\section{References}

Alexander-Passe, N. (2008). The Sources of Manifestations of Stress amongst School-Aged Dyslexics, Compared to Sibling Controls. Dyslexia, 14(4), 291-313.

Brooks, G. (2013). What Works for Children and Young People with Literacy Difficulties? $4^{\text {th }}$ Edition. London: The Dyslexia-SpLD Trust.

Creswell, J. W., \& Poth, C. N. (2018). Qualitative Inquiry and Research Design: Choosing among Five Approaches. $4^{\text {th }}$ Edition. Thousand Oaks CA: SAGE Publications.

Dahlberg, K., Dahlberg, H., \& Nyström, M. (2008). Reflective Lifeworld Research. Lund: Studentlitteratur. 
Duff, F. J., \& Clarke, P. J. (2011). Practitioner Review: Reading Disorders: What are the Effective Interventions and how should they be Implemented and Evaluated? Journal of Child Psychology and Psychiatry, 52(1), 3-12.

Dukes, S. (1984). Phenomenological Methodology in the Human Sciences. Journal of Religion and Health, 23(3), 197-203.

Elliott, J. G., \& Grigorenko, E. L. (2014). The Dyslexia Debate. New York: Cambridge University Press.

Fletcher, J. M., Lyon, G. R., Fuchs, L. S., \& Barnes, M. A. (2019). Learning Disabilities: From Identification to Intervention. $2^{\text {nd }}$ Edition. New York: Guilford Press.

Giorgio, A. (2009). The Descriptive Phenomenological Method in Psychology: A Modified Husserlian Approach. Pittsburgh: Duquesne University Press.

Groenewald, T. (2004). A Phenomenological Research Design Illustrated. International Journal of Qualitative Methods, 3(1), 42-55.

Haug, P. (2020). Inclusion in Norwegian Schools: Pupils' Experiences of their Learning Environment. International Journal of Primary, Elementary and Early Years Education, 48(3), 303-315.

Hulme, C., \& Melby-Lervåg, M. (2015). Effects from Interventions for Psychological Learning and Behavioural Disorders in Children. In A. Thapar, D. S. Pine, J. F. Leckman, S. Scott, M. J. Snowling, \& E. Taylor (eds.), Rutter's Child and Adolescent Psychiatry (6 ${ }^{\text {th }}$ Edition) (pp. 533-545). Chichester: Wiley Blackwell.

Hulme, C., \& Snowling, M. J. (2016). Reading Disorders and Dyslexia. Current Opinion in Pediatrics, 28(6), 731-735.

Kim, J. A., \& Lorsbach, A.,W. (2005). Writing Self-Efficacy in Young Children: Issues for the Early Grades Environment. Learning Environments Research, 8(2), 157-175.

Knight, C. (2018). What is Dyslexia? An Exploration of the Relationship between Teachers' Understandings of Dyslexia and their Training Experiences. Dyslexia, 24(3), 207-219.

Morris, D., \& Turnbull, P. (2006). Clinical Experiences of Students with Dyslexia. Journal of Advanced Nursing, 54(2), 238-247.

Peterson, R. L., \& Pennington, B. F. (2012). Developmental Dyslexia. The Lancet, 379 (9830), 1997-2007.

Reid, G. (2011). Dyslexia. $3^{\text {rd }}$ Edition. London: Continuum.

Ridscale, J. (2005). Dyslexia and Self-Esteem. In M. Turner \& J. Rack (eds.), The Study of Dyslexia. New York: Springer.

Skaalvik, S. (2004) Reading Problems in School Children and Adults: Experiences, SelfPerceptions and Strategies. Social Psychology of Education, 7(2), 105-125.

Snowling, M. J., \& Melby-Lervåg, M. (2016). Oral Language Deficits in Familial Dyslexia: A Meta-Analysis and Review. Psychological Bulletin, 142(5), 498-545.

Torgesen, J. K. (2002). The Prevention of Reading Difficulties. Journal of School Psychology, 40(1), 7-26.

UNESCO (1994). The Salamanca Statement and Framework for Action on Special Needs Education. Paris: UNESCO.

Van Manen M. (1997). Researching Lived Experience: Human Science for an Action Sensitive Pedagogy. $2^{\text {nd }}$ Edition. London: Althouse Press.

Van Manen, M. (2014). Phenomenology of Practice: Meaning-Giving Methods in Phenomenological Research and Writing. London: Taylor \& Francis Group.

Wagner, R. K., Zirps, F. A., Edwards, A. A., Wood, S. G., Joyner, R. E., Becker, B., et al. (2020). The Prevalence of Dyslexia: A New Approach to its Estimation. Journal of Learning Disabilities, 53(5), 354-365. 
Vol. 9, No. 1 Lyngsnes \& Skjelvåg: Being a Dyslectic in Norwegian Secondary School

White, J., Mather, N., \& Kirkpatrick, J. (2020). Preservice Educators' and Noneducators' Knowledge and Perceptions of Responsibility about Dyslexia. Dyslexia, 26(2), 220242.

World Health Organization - WHO (2018). International Statistical Classification of Diseases and Related Health Problems $11^{\text {th }}$ Revision (ICD-11). WHO. 